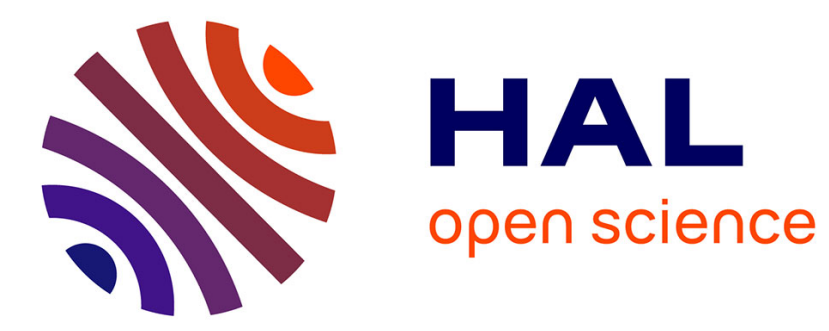

\title{
Information Support for Supplier Kit Preparation
}

\author{
Maria Kollberg Thomassen, Lars Skjelstad, Erlend Gjønnes
}

\section{To cite this version:}

Maria Kollberg Thomassen, Lars Skjelstad, Erlend Gjønnes. Information Support for Supplier Kit Preparation. IFIP International Conference on Advances in Production Management Systems (APMS), Aug 2018, Seoul, South Korea. pp.241-248, 10.1007/978-3-319-99707-0_30 . hal-02177839

\section{HAL Id: hal-02177839 \\ https://hal.inria.fr/hal-02177839}

Submitted on 9 Jul 2019

HAL is a multi-disciplinary open access archive for the deposit and dissemination of scientific research documents, whether they are published or not. The documents may come from teaching and research institutions in France or abroad, or from public or private research centers.
L'archive ouverte pluridisciplinaire HAL, est destinée au dépôt et à la diffusion de documents scientifiques de niveau recherche, publiés ou non, émanant des établissements d'enseignement et de recherche français ou étrangers, des laboratoires publics ou privés. 


\title{
Information Support for Supplier Kit Preparation
}

\author{
Maria Kollberg Thomassen ${ }^{1, *}$, Lars Skjelstad ${ }^{1}$, Erlend Gjønnes ${ }^{2}$ \\ ${ }^{1}$ SINTEF Technology and Society, S.P. Andersens veg 5, 7031 Trondheim, Norway \\ \{maria.thomassen, lars.skjelstad\}@sintef.no \\ ${ }^{2}$ Orkel AS, Johan Gjønnes' veg 25, 7320 Fannrem, Norway \\ Erlend@orkel.no
}

\begin{abstract}
Information support in kit preparation is critical for the design of efficient kitting systems. Existing literature is dominated by studies that address inhouse kitting and order picking support in warehouse settings and that are based upon laboratory experiments. This study explores critical aspects of information support for kit preparation outsourced to partners in the supply chain based upon empirical evidence of a web application for kitting adopted in a real-life case of a manufacturer and a supplier. Detailed insights to kitting efficiency, information sharing and user acceptance are presented. Critical aspects are identified primarily related to the relationship and interaction between companies, quality of information sharing, usefulness, parts identification efficiency, and joint improvement and development efforts. This work highlights the importance of considering supply chain information sharing in outsourced kitting.
\end{abstract}

Keywords: Parts Logistics, Kitting, Supply Chain Collaboration

\section{Introduction}

Kitting is a materials handling policy, where components are delivered to the shop floor in pre-determined quantities that are placed together in dedicated containers, to avoid keeping components inventories at assembly stations [1]. The policy is especially suitable in mixed-model assembly situations, typically characterized by small batch sizes and large product variety, such as mass customization settings [2].

Efficient kit preparation is essential for high performance kitting systems. Information systems for picking support is recognized as a critical design factor [3, 4]. There is a large amount of research addressing order picking support in warehouse settings. Rapid developments of digitalization drives the adoption of smart digital tools, and several recent studies investigate the use of such tools in order picking [e.g. 5, 6]. However, printed picking lists are still common, and research dealing with information support in kit preparation situations is scarce (see for instance [7]).

adfa, p. 1, 2011.

(C) Springer-Verlag Berlin Heidelberg 2011 
Most empirical studies dealing with picking support are based upon laboratory experiments, and there is thus a need for more research on real-world adoption in industrial settings. Existing research is also mainly concentrated to in-house operations. Therefore, research on information support when kit preparation is outsourced to an external party, for instance when suppliers or third-party logistics providers are involved, is scarce.

The purpose of this research is to investigate key information support aspects for kit preparation in supply chain settings by exploring the adoption of such support in a reallife case. This work is expected to contribute to further development of information support when kitting operations are outsourced to a supplier or a third party.

Even though kitting may be related to logistics operations in business-to-consumer settings i.e. kit-to-customer, the scope of this study includes kit-to-manufacturing, that implies pulling parts together in kit containers which are delivered to the shop floor to support assembly operations [1].

\section{Research Approach}

A case study approach is applied including a literature review of key information support aspects for kit preparation and information sharing in supply chains. The empirical study focuses on the adoption of a support tool for kit preparation in a dyadic relationship with a manufacturing company and one of its key suppliers. The companies are selected due to their participation in a joint R\&D project dealing with efficient logistics in the supply chain.

The companies have been involved in the research process; company representatives have served as main sources of data collection. Empirical findings have been documented and archived after discussions with the companies. Several sources of information have been combined; data is mainly collected by interviews, discussions and direct observations, in addition to data transcripts and e-mails. Key informants from the companies have confirmed the description of the case presented. Findings regarding relevant aspects in the case are also discussed in view of existing literature.

Empirical data was mainly collected from interviews, workshops and discussions with key informants, and factory visits in the companies between 2016 and 2018. About ten workshops of 2-4 hours were held together with researchers and representatives of the two companies; the work group included the plant managers of both companies, the manufacturer's purchasing manager, the technical manager and the customer service representative of the supplier, and several employees in production, picking and goods reception. Most of the workshops were combined with factory visits.

Empirical information is also gathered from photos, documentation, presentations, data extracts from the manufacturer's ERP system and e-mails. Measurements data of kitting costs between September 2016 and December 2017 were gathered.

The manufacturing company, Orkel, assembles large machinery equipment and the supplier, Skala, delivers steel components to Orkel. Components, which are manufactured by laser cutting and bending of steel plates, are sorted into kits before delivered 
to Orkel. Complexity is high due to high variation in the number of parts per kit and sizes of parts and kits.

Orkel has developed a mobile web application, the Supplier Kitting Application (SKA), to support kitting at Skala. It is accessed via a tablet and shows order and kit information and drawings of components. A picker, who is responsible for kit preparation, mainly uses traditional printed paper lists to identify parts. Each part is also marked with a laser printed number to facilitate identification. The main purpose of the SKA is to give the picker easy access to drawings of parts in case of uncertainty or difficulties finding parts and serves as a complement to paper lists.

\section{Literature Review}

\subsection{Information Support in Kit Preparation}

Kitting means delivering components and subassemblies to the shop floor in predetermined quantities that are placed together in specific containers and a kit is a specific collection of components and/or subassemblies that together support one or more assembly operations for a given product or shop order [1]. In kitting, materials are centrally stored and kits are typically prepared in a stockroom based upon a pick list, and are delivered to the assembly line according to production schedule [2].

Efficient preparation of kits is essential due to increased costs related to extra parts handling, labor intensive and non-productive work [2, 8]. Kitting efficiency is influenced by several factors, for instance the amount of kits, kitting area, picking sequence, storage and racks, batch size, kit container and carrier [3, 4, 9]. Also, information support is often recognized as a critical factor [3, 4]. It involves how the picker receives and understands information of which parts to pick for each order [3]. Issues may be related to how information is communicated to the picker and that experienced pickers with comprehensive understanding of underlying product structures tend to neglect the picking information [3].

Efficient support for pickers is a major challenge in warehouse operations. Due to rapid developments in automated and advanced order picking support, many companies have adopted pick-by-light and pick-by-voice systems and there is also a growing interest for pick-by-vision or augmented reality systems [10]. However, manual picking and printed lists is still used. Common aspects related to information picking support include picking time, picking error rate or accuracy and cognitive load [5-7, 10, 11]. Considerations should also be taken to user acceptance and motivation, learning success, technology acceptance, usability and ergonomics [10].

\subsection{Supply Chain Information Sharing}

Since it is beneficial to locate kitting operations close to the assembly line, it is often carried out in-house by the manufacturer [2]. Kitting operations can also be outsourced to an external party, for example a supplier or a third-party logistics services provider [12]. It is assumed that outsourced kitting operations may imply challenges related to 
information support. For example, a picker at a supplier may have more limited understanding of the manufacturers products and product structures compared to an in-house picker. It may also be more difficult to solve issues that may occur during kitting or have access to additional information due to physical distances between two different organizations. A supplier is dependent upon that the manufacturer provides necessary information to the supplier to perform kitting in an efficient manner.

Information-sharing is recognized as a key driver of supply chain integration and collaboration [13]. Even though information-sharing often involves manufacturers sharing demand information, plans and forecasts with suppliers, suppliers may also share information such as status information or delivery plans with their customers.

To ensure high usage of shared information its quality is critical; information must be accurate, convenient to access, reliable and in time [14, 15]. Information technology may be used to enhance quality as well as information sharing, and relationship quality in terms of for example trust or length, is further critical for information sharing, information quality and information technology [14].

\section{$4 \quad$ Case Findings}

\subsection{Picking Efficiency and Accuracy}

The manufacturer's measurements of supplier kitting costs, and the time for adopting the web application (mid-December 2016), are shown in Fig. 1. Overall, by the end of the measurement period (August 2017), average costs had decreased by about 29 percent compared to the period before the tool was introduced (mid-September to midDecember 2016), and by about 46 percent compared to the peak of average costs (February 2017).

It is probably not the web application alone that has contributed to reduced kitting costs, but rather several improvements that have been implemented. For example, the number of order lines per order has increased during the same period. Also, in June 2017, the delivery frequency was changed based upon completed kits instead of deliveries of completed orders and a new kitting area at the supplier plant was established.

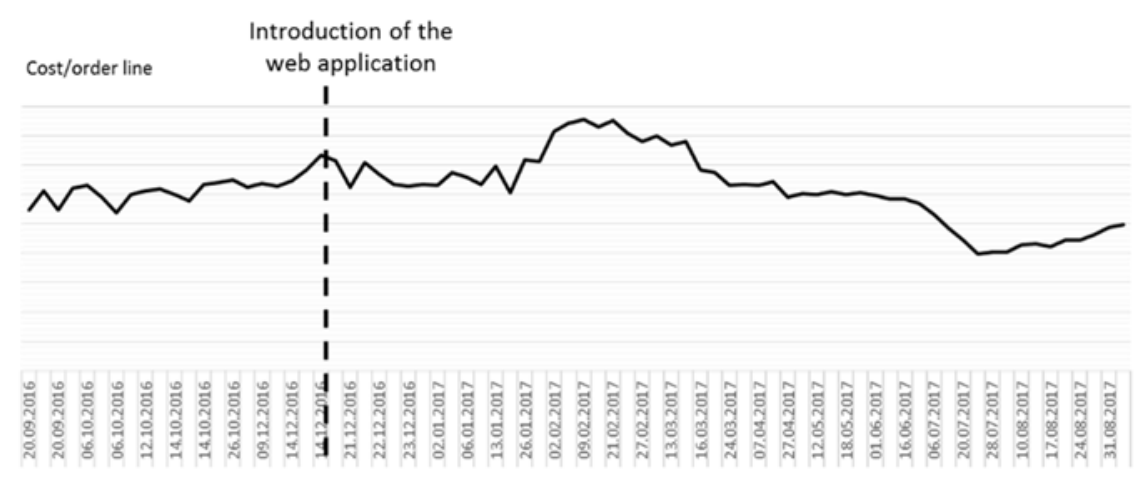

Fig. 1. Kitting cost per order line between September 2016 and August 2017 
An explanation to increased costs is that the picker spent more time using the web application to identify parts in the beginning. The picker must use both hands to access the tablet, so it is not possible to pick at the same time. The application thus led to reduced efficiency on a short term. As the picker became more familiar with the tool and learned to identify parts without using the tool, he spent less time to use the tool.

In addition, even though the picker has no conception of product structure, he has trained his ability to visually recognize combinations of parts of the kits based upon the paper list only. Also, since the parts have printed identification number and are delivered directly to the kitting area for kitting the same or the following day as produced, the picker is exposed to a limited number of parts and numbers.

Efficiency is also affected by that the picker uses the tool to give feedback on kitting status to the manufacturer. It can be assumed that this has slowed down kitting as the picker stops picking to mark completed kits. However, this has led to that kits could be delivered more frequently, which in turn implied reduced work in progress.

Accuracy has not been measured since errors are generally rare. The web application may have contributed to higher accuracy, in combination with several other improvements in the kitting system including more frequent deliveries of kits, marking and organization of kits in pallets, and so on.

\subsection{Information Sharing}

The content of information provided by the manufacturer includes a list of orders with kit numbers and specification of parts of each kit, Fig. 2. The picker can choose to access drawings of each part to get a visual presentation of that part in case of uncertainty.

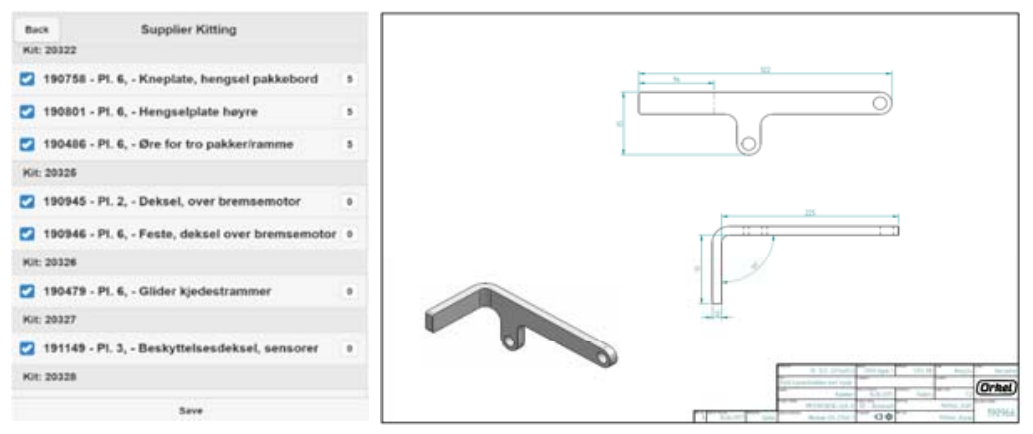

Fig. 2. Example screen shots from web application; list of kits and components and drawing of a component

Quality of information is ensured by that the manufacturer has developed the web application for the supplier and thus provides the necessary information via the application. It is integrated with the manufacturer's ERP system and updated files are continuously transferred to the database that is accessible via the web application. The manufacturer thus ensures that the picker always has online access to up-to-date information with the latest version of kit information and drawings. 
The web application further provides additional value to the manufacturer; the manufacturer can easily get an overview of status of kit preparation at the supplier in real time. This requires that the picker checks out completed kits in the web application in a timely manner.

The web application has had a positive contribution to the collaborative relationship and communication between the companies; both companies experience positive value from the new kitting support and therefore they also invest in improving the web application.

The information content has not changed during the investigation. However, the companies have discussed how the web application can be further adjusted to substitute the use of the paper picking list at Skala and have started to test an updated version with more adjusted information, where specific materials and bended parts are specifically marked in the list.

The drawings have contributed to reducing the cognitive load of identifying parts. However, alternatives to detailed drawings have been discussed since the picker often only needs a basic visual conception of parts, related to size, form and geometry, rather than a full specification. Tests of using simple photos of parts in kits are planned and may substitute or serve as a simplified complement to detailed drawings. Photos may also give the picker an overview of the final kit, which is missing in the current version of the application.

\subsection{User acceptance}

The picker has found the tool useful for kit preparation and has been motivated to use it. The tool is easy to use as the picker has not experienced any trouble to use it. The picker has gained more experience over time and has become less dependent of the web application, indicating positive learning effects.

The picker also gives feedback to the manufacturer of further improvements of the application. Moreover, the picker checks out completed kits continuously, since he is aware of that the manufacturer can access this information, although it requires extra time.

In view of ergonomics, the picker must use both hands to use the tablet and this interrupts the kitting activity. The companies have discussed alternatives to the tablet and plan to test the web application in various technologies of head mounted tablets to support kitting.

\section{$5 \quad$ Discussion and Conclusion}

The study shows how information support provided by a manufacturer can contribute to increase efficiency of supplier kitting operations. Key aspects identified include;

- the initiative is initiated by the manufacturer, with a good understanding of specific needs of the supplier for the development of the tool

- the supplier utilizes the information support as intended and finds it usable and useful 
- the supplier uses the support as a learning tool, to improve the ability to recognize parts

- the supplier understands the information needs of the manufacturer and utilizes the tool to share information with the manufacturer

- the manufacturer ensures the quality of information sharing by ERP integration

- the companies prioritize and make joint efforts to improve kitting performance and parts supply efficiency

- the companies make joint efforts to utilize the tool to further develop information sharing practices

While existing research mainly deals with picking information support in in-house logistics and in laboratory settings, this study adds further insights to settings where kit preparation is outsourced based upon a real-life case of practical adoption. The identified aspects bring further details regarding supply chain considerations related to kit preparation. The study especially emphasizes the importance of information sharing and quality in supply chain integration and collaboration, which is also highlighted in existing supply chain research $[14,15]$. The identified information sharing aspects provide additional understanding to kit preparation information support in outsourced situations.

Generally, findings are line with existing in-house logistics research highlighting efficiency gains from information support in kitting and picking situations [6, 7]. Findings also confirm that experienced pickers may have different picking support needs compared to the needs of less experienced pickers [3]. Findings further reveal how user acceptance seem to depend upon usability and usefulness of the support and reduced cognitive load. This is in line with research emphasizing the importance of human factors [10].

Aspects presented in this study may be used in further research on the development and implementation of information support for outsourced kitting situations. Managers may find the results useful for implementing kitting support in such settings.

Findings are based upon empirical data from one case. Further empirical research is suggested to develop more insight to how identified aspects vary in different outsourcing supply chain settings. Moreover, the aspect of changing picking efficiency and needs of information support over time was highlighted in this study. It is therefore suggested that further research should include longitudinal studies of information support adoption in practice. The study shows how an information support tool for kitting initiated by a manufacturer can contribute to improved material flows and enhanced collaboration with suppliers. Further research is planned to test several types of information support equipment, such as smart glasses and head-mounted tablets, for outsourced picking.

Acknowledgements. This work was supported by the User-driven Research based Innovation (BIA) program of the Research Council of Norway. 


\section{References}

1. Bozer, Y.A., McGinnis, L.F.: Kitting versus line stocking: a conceptual framework and a descriptive model. International Journal of Production Economics 28(1), 1-19 (1992). doi: 10.1016/0925-5273(92)90109-K

2. Caputo, A.C., Pelagagge, P.M.: A methodology for selecting assembly systems feeding policy. Industrial Management \& Data Systems 111(1), 84-112 (2011). doi: 10.1108/02635571111099749

3. Brynzér, H., Johansson, M.I.: Design and performance of kitting and order picking systems. International Journal of Production Economics 41(1), 115-125 (1995). doi: 10.1016/09255273(95)00083-6

4. Hanson, R., Medbo, L.: Aspects Influencing Man-hour Efficiency of Kit Preparation for Mixed-model Assembly. Procedia CIRP 44, 353-358 (2016). doi: 10.1016/j.procir.2016.02.064

5. Funk, M., Mayer, S., Nistor, M, Schmidt, A.: Mobile in-situ pick-by-vision: Order picking support using a projector helmet. In: Proceedings of the 9th ACM International Conference on PErvasive Technologies Related to Assistive Environments. ACM New York (2016). doi: 10.1145/2910674.2910730

6. Guo, A., Raghu, S., Xie, X., Ismail, S., Luo, X., Simoneau, J., Gilliland, S., Baumann, H., Southern,C., Starner,T.: A comparison of order picking assisted by head-up display (HUD), cart-mounted display (CMD), light, and paper pick list. In: Proceedings of the 2014 ACM International Symposium on Wearable Computers, pp. 71-78. ACM New York (2014). doi: $10.1145 / 2634317.2634321$

7. Hanson, R., Falkenström, W., Miettinen, M.: Augmented reality as a means of conveying picking information in kit preparation for mixed-model assembly. Computers \& Industrial Engineering 113, 570-575 (2017). doi: 10.1016/j.cie.2017.09.048

8. Kilic, H.S., Durmusoglu, M.B.: Advances in assembly line parts feeding policies: a literature review. Assembly Automation 35(1), 57-68 (2015). doi: 10.1108/AA-05-2014-047

9. Kilic, H.S., Durmusoglu, M.B.: Design of kitting system in lean-based assembly lines. Assembly Automation 32(3), 226-234 (2012). doi: 10.1108/01445151211244357

10. Reif, R., Walch, D.: Augmented \& Virtual Reality applications in the field of logistics. The Visual Computer 24(11), 987-994 (2008). doi: 10.1007/s00371-008-0271-7

11. Reif, R., Günthner, W. A., Schwerdtfeger, B., Klinker, G.: Evaluation of an augmented reality supported picking system under practical conditions. Computer Graphics Forum 29(1), 2-12 (2010). doi: 10.1111/j.1467-8659.2009.01538.x

12. Klingenberg, W., Boksma, J.-D.: A conceptual framework for outsourcing of materials handling activities in automotive: differentiation and implementation. International Journal of Production Research 48(16), 4877-4899 (2010). doi: 10.1080/00207540903067177

13. Cao, M., Zhang, Q.: Supply Chain Collaboration: Roles of Interorganizational Systems, Trust, and Collaborative Culture. Springer London (2012)

14. Li, S., Lin, B.: Accessing information sharing and information quality in supply chain management. Decision support systems 42(3), 1641-1656 (2006). doi: 10.1016/j.dss.2006.02.011

15. Forslund, H., Jonsson, P.: The impact of forecast information quality on supply chain performance. International Journal of Operations \& Production Management 27(1), 90-107, (2007). doi: 10.1108/01443570710714556 